\title{
O OLHAR DE UM LICENCIANDO PARA O ENSINO DE QUÍMICA E A EDUCAÇÃO AMBIENTAL
}

\author{
Fátima de Paiva Canesin ${ }^{1}$, Oswald César Vianna Silva ${ }^{2}$, Rose Mary Latini ${ }^{1,3}$ \\ ${ }^{1}$ Universidade Federal Fluminense/Departamento de Físico-Química/fatimacanesin@ yahoo.com.br \\ ${ }^{2}$ Universidade Federal Fluminense/Instituto de Química/zarcevi@yahoo.com.br \\ ${ }^{3}$ UNIPLI/Mestrado Profissional em Ensino de Ciências da Saúde e do Ambiente/rmlatini@uol.com.br.
}

\begin{abstract}
Resumo
A percepção ambiental é a etapa inicial para uma atuação mais ampla da Educação Ambiental que deve estar inserida em todos os seguimentos da escola, desde o fundamental ao ensino médio. O profissional da química é um dos atores que pode atuar como motivador da compreensão do meio ambiente e as suas relações com a química. $\mathrm{O}$ trabalho relata a prática de um licenciando em Química, da Universidade Federal Fluminense ao elaborar aulas expositivas contextualizando conceitos químicos com meio ambiente. Um jogo didático foi desenvolvido e aplicado com o objetivo de ser mais um recurso pedagógico na construção de conhecimentos acerca de problemas ambientais. O jogo é do tipo de trilha e os alunos jogam em grupos, tendo o professor como mediador, respondendo perguntas com as temáticas ambientais: resíduos sólidos, efeito estufa, chuva ácida, desperdício de água. Participaram da pesquisa alunos da segunda série de uma escola pública da cidade de Niterói/RJ. Os resultados apontam que a aproximação do licenciando com o cenário escolar, favoreceu a constituição de uma prática reflexiva para o professor em formação.
\end{abstract}

Palavras-chave: Educação Ambiental, Jogo Didático, Ensino de Química

\begin{abstract}
The environmental perception is the first step to a wider performance in Environmental Education as a theme applied in all sections of instruction, from elementary to high school. The chemistry professional is a very important person, who can motivate the comprehension of the environment and its relations with chemistry. This work relates to the experience of a licensing student of Chemistry, who developed a didactic game based in this thematic. The game was played with some high school students of the "Colégio Estadual Henrique Laje", an important public school in Niterói, Rio de Janeiro, Brazil. A questionnaire was applied in class to diagnose their environmental perception. After that, two seminaries where shown to the students, about water and its waste, greenhouse effect, acid rain, global warming, importance of the ozone layer, solid residues and recycling, in order to facilitate the construction on knowledge. The game is composed of a board that works as a track, which is projected with the use of an overhead projector. The students play in groups, answering to questions related to the environmental themes and having the teacher as a mediator. The game and the perception acquired were validated a second half-structured questionnaire. The development of an interventionist methodology of research to be realized in schools by a licensing allows the formation of a professional who reflects about his future pedagogic practices.
\end{abstract}

Keywords: Environmental Education, Educational Games, Chemistry 


\section{INTRODUÇÃO}

O Sistema Nacional de Avaliação de Educação Básica, SAEB, foi iniciado na década de 90 e age como uma referência nacional; sobre os conteúdos praticados e indicados pelas escolas brasileiras. Com o SAEB é possível realizar cruzamentos entre conteúdos e competências, referidos aos diferentes níveis e aos diferentes ciclos de avaliação. O objetivo proposto pelo SAEB para o curso de Química indica que a aprendizagem de Química pressupõe a compreensão de conceitos para a realização de uma releitura do mundo em que se vive e possibilita a inserção do aluno para um viver integrado entre a sociedade e o meio ambiente. Neste contexto, o profissional da Química é um dos principais atores que pode atuar como um mediador da compreensão do meio ambiente e as suas relações com a Química. Atualmente, alguns professores definem temas-chave para que em cima deles possam interagir diversas disciplinas criando uma maior integração entre disciplinas estabelecendo, junto de práticas docentes e do desenvolvimento do trabalho didático-pedagógico, subsídios para a transformação do indivíduo.

Para tal, o profissional deve estar apto para articular a ciência formal com conhecimentos multidisciplinares na forma de interagir com outras áreas do conhecimento possibilitando ao aluno ter um novo olhar no espaço-tempo que está situado. A Educação Ambiental, por sua vez, traz uma nova proposta ao sistema educacional e, Diaz (2002) recomenda que a escola forme indivíduos com capacidade de intervenção na realidade global e complexa da sociedade. Assim, urge formar novos educadores com uma visão voltada para a inserção do homem no meio ambiente através de novas práticas pedagógicas que possam atuar numa escola mais moderna e comprometida.

Diante das respostas que a natureza vem apresentando, desde o fim da década passada, provenientes de ações perversas contra a natureza, a humanidade sentiu a importância de uma reflexão com relação à questão ambiental procurando soluções como a busca de um desenvolvimento sustentável e metodologias de desenvolvimento limpo. Hoje as questões do aquecimento global, escassez de água e o destino dos resíduos estão veiculados na mídia escrita e falada identificando que o comportamento atual da sociedade é o responsável pelas modificações climáticas em todo o planeta com consequências desastrosas para as futuras gerações. Neste contexto, a Educação 
Ambiental surge com a possibilidade de construção de novos valores e atitudes, gerando novos padrões éticos a serem construídos e vividos individual e coletivamente.

Pela Lei Nº 9795 de 1999, a Educação Ambiental é definida como: '’Processos por meio dos quais o individuo e a coletividade constrói valores sociais, conhecimentos, habilidades, atitudes e competências voltadas para a conservação do meio ambiente, bem de uso comum do povo, essencial à sadia qualidade de vida e sua sustentabilidade."

Assim a lei 9795, que instituiu a Política Nacional de Educação Ambiental, oferece amparo legal à EA, responsabilizando e envolvendo todos os setores da sociedade, e incorporando oficialmente a EA nos sistemas de ensino. Os Parâmetros Curriculares Nacionais, PCN incluem a Educação Ambiental no sentido de favorecer o engajamento político-social e aponta o professor como o ator desta nova visão da educação voltada para a formação de cidadania.

Para Ovalles (1995), a Educação Ambiental assume um caráter mais realista baseado na procura do equilíbrio entre o homem e o ambiente, visando à construção de um futuro pensado e vivido numa lógica de desenvolvimento e progresso em concomitância com a sustentabilidade global.

A educação ambiental deve tratar das questões globais críticas, suas causas e inter-relações em uma perspectiva sistêmica, em seu contexto social e histórico. Aspectos primordiais relacionados com o desenvolvimento e o meio ambiente, tais como população, saúde, paz, direitos humanos, democracia, fome, degradação da flora e da fauna, devem ser abordados dessa maneira, (OVALES, 1995).

A implantação de um programa de EA na escola não é muito fácil, uma vez que se tem a necessidade de capacitar os professores para atuarem junto à comunidade de alunos. Ainda, para que um projeto de EA tenha um efeito educativo é importante dar continuidade ao mesmo, com a manutenção das atividades de sensibilização desenvolvidas e a formação de um ecotime motivador e responsável pelas mudanças de paradigmas com contínua reflexão das novas práticas vencendo as barreiras iniciais de implantar a EA com atividades pontuais que não se mantém por muito tempo e não funcionam como agente transformador. Para que um professor incorpore a EA na sua prática pedagógica também ele tem que ter sido motivado para tal. Os cursos de licenciatura não desenvolvem nos licenciandos a habilidade para este tipo de trabalho. A Universidade tem se omitido na formação de profissionais com olhares mais críticos para a realidade do ensino e do meio ambiente. Os saberes para a implantação de um 
programa de EA na escola são aprendidos pela vivência e transformados a partir das mais variadas situações vividas. Em algumas grades curriculares dos cursos de licenciatura em química, a disciplina de Química Ambiental é introduzida sem o foco de contextualização dos conteúdos praticados com um novo saber voltado para a cidadania e o redimensionamento do futuro educador na sociedade.

O objetivo deste trabalho é fazer um relato analisado da prática de um licenciando, durante o seu trabalho de monografia no Curso de Licenciatura em Química/UFF, a partir da inserção da temática ambiental no ensino de Química realizado em uma escola pública do estado do Rio de Janeiro.

\section{EDUCAÇÃO AMBIENTAL E A PRÁTICA PEDAGógICA}

Escolher uma metodologia de pesquisa, para ser desenvolvida no ambiente escolar por um licenciando, deve levar em consideração que o objetivo maior é a formação de um profissional reflexivo quanto a sua futura prática, a qual possibilita, principalmente no campo educacional, um salto qualitativo, pois a busca de dados e o processo de apreensão da realidade serão os subsídios necessários para a construção de uma abordagem pedagógica que envolva a questão ambiental.

\footnotetext{
"Educar pela pesquisa tem como condição essencial primeira que o profissional da educação seja pesquisador, ou seja, maneje a pesquisa como princípio científico e educativo e a tenha como atitude cotidiana. Não é o caso de fazer dele um pesquisador "profissional", sobretudo na educação básica, já que não a cultiva em si, mas como instrumento principal do processo educativo", DEMO (1996).
}

A aproximação do licenciando com o cenário escolar se deu através de aulas, onde se trabalhou conteúdos da química, amplamente contextualizados com problemas ambientais. Participaram desta pesquisa os alunos da segunda série do Ensino Médio, do noturno, do Escola Técnica Estadual Henrique Laje/FAETEC, em Niterói. Nestes encontros foram explorados os assuntos resíduos sólidos, aquecimento global, chuva ácida, efeito estufa, consumo de água e reciclagem contextualizando com exemplos presentes no cotidiano dos alunos. Cabe ressaltar, que os conteúdos da Química, tais como Funções Inorgânicas, já haviam sido trabalhados, anteriormente, pelo professor da turma. Assim, foi três o número de encontros do licenciando com a turma, sendo que cada encontro corresponde a duas horas aulas de 50 minutos, totalizando, portanto, 6 horas/aulas. 
Assim a observação participante, como técnica de pesquisa qualitativa, permitiu a aproximação do pesquisador com o seu objeto de estudo facilitando a apreensão da realidade concreta, na qual estão inseridos os alunos. (LÜDKE E ANDRÉ, 1986). Em um primeiro momento foi levantado o conhecimento prévio dos alunos sobre problemas ambientais, tais como: água, ar e resíduos, utilizando-se um questionário semi estruturado, com 18 questões com a finalidade de identificar os saberes da turma a respeito de tais temas. A seguir, foram ministradas aulas expositivas e interativas sobre esses temas, articulando conteúdos de química, e problemas ambientais. As aulas foram preparadas pelo licenciando na forma de apresentação criadas com o programa "Power Point".

A apresentação para o tema Resíduos Sólidos enfocou a questão da disposição dos resíduos, o tempo de permanência de diferentes materiais no ambiente e a importância da reciclagem. Para os materiais plásticos foram introduzidos as reações de polimerização com apresentação das moléculas, os símbolos para reciclagem e a presença dos polímeros no nosso cotidiano. A aula com o tema Atmosfera explorou o efeito estufa, a chuva ácida e suas consequências. Algumas reações químicas que ocorrem na atmosfera foram mostradas para explorar os conceitos de funções químicas, de $\mathrm{pH}$ e nomenclatura. Nos slides sobre Água o mote principal foi a qualidade da água, sua escassez e um consumo mais consciente, onde se trabalhou conteúdos da química, amplamente contextualizados com as questões de poluição e tratamento de água.

Buscou-se logo depois da última apresentação, a aplicação de um jogo didático como um instrumento de observação e como outro recurso além da aula, só que trabalhando estes mesmos conteúdos de forma lúdica. O jogo foi apresentado à turma que o jogou, num tempo de aula. Após as aulas expositivas e o uso do jogo, novo questionário fechado foi aplicado, com dezoito perguntas, sendo três formuladas para investigar se o jogo foi aprovado como um recurso didático e as demais questões com os conteúdos das aulas e as perguntas formuladas no jogo. A função do segundo questionário foi avaliar a contribuição da prática docente desenvolvida pelo licenciando para as relações de ensino-aprendizagem.

\section{O JOGO: "TRILHA AMBIENTAL"}


A idéia de desenvolver um jogo com propósitos educacionais permite que o jogador aprenda enquanto realiza uma determinada atividade, pois existe uma contextualização do que é apresentado como conteúdo didático e o desafio de vencer o jogo possibilitando uma construção do conhecimento a partir de uma atividade lúdica.

$\mathrm{O}$ aluno jogador passa a se interessar pelo tema com um interesse em vencer o desafio proposto. Sobre o papel das regras dos jogos, Vigotski (2003) argumenta que:

....ao subordinar todo o comportamento a certas regras convencionais, ele é o primeiro a ensinar uma conduta racional e consciente. Para a criança, o jogo é a primeira escola de pensamento. Todo pensamento surge como resposta a um problema, como resultado de um novo ou difícil contato com os elementos do meio. ...Em outras palavras, o jogo [com regras] é um sistema racional e adequado, planejado, coordenado socialmente, subordinado a certas regras.

Levar a EA na escola através de um jogo didático, que reúne desde aspectos lúdicos aos cognitivos para o ensino e a aprendizagem de conceitos ambientais, e as relações do homem com o meio, favorece a motivação interna, o raciocínio, a argumentação e a interação entre alunos e professores. Segundo Miranda:

\begin{abstract}
“(...) mediante o jogo didático, vários objetivos podem ser atingidos, relacionados à cognição (desenvolvimento da inteligência e da personalidade, fundamentais para a construção de conhecimentos); afeição (desenvolvimento da sensibilidade e da estima e atuação no sentido de estreitar laços de amizade e afetividade); socialização (simulação devida em grupo); motivação (envolvimento da ação, do desfio e mobilização da curiosidade) e criatividade.” (MIRANDA, 2001 apud CAMPOS, 2003)
\end{abstract}

Após avaliarmos diferentes formas de apresentar um jogo didático que pudesse ser jogado com a participação de toda a turma, ficando o professor como mediador deste, foi escolhido um jogo tipo "Trilha". Este formato de jogo faz parte do cotidiano de crianças e jovens que conhecem bem a dinâmica do mesmo. O tempo previsto é de uma aula de 50 minutos. O jogo consiste de um tabuleiro (transparência), 5 marcadores de formatos diferentes, 15 cartas verdes, 10 cartas vermelhas, 1 dado, um retroprojetor e uma tela.

A trilha foi desenhada no computador sendo constituída de casas brancas, verdes e vermelhas. Esta trilha foi impressa numa transparência e foi apresentada com o auxílio de um retroprojetor. Desta forma toda a turma dividida em grupos visualiza a trilha e participa do jogo. 

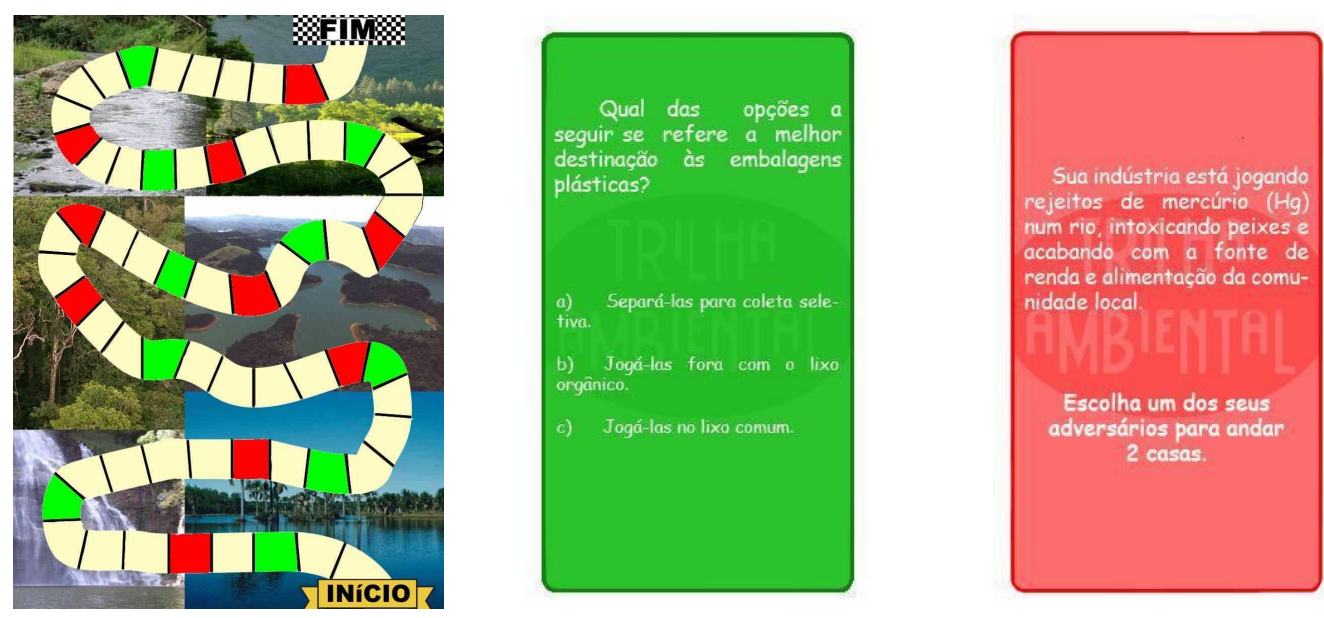

Figura 1: Tabuleiro do jogo "Trilha Ambiental” Cartas Verdes e Cartas Vermelhas

O jogador percorre a trilha com o auxilio de um pino que anda pelas casas da trilha de acordo com o número que saiu ao jogar o dado. O objetivo do jogo é chegar ao final da trilha com o maior número de cartas verdes que representam respostas corretas as perguntas sobre o meio ambiente. Nas casas verdes o jogador responde as perguntas, das cartas verdes, formuladas com os conteúdos apresentados em momentos anteriores com a turma. As cartas vermelhas, obtidas quando da parada na casa vermelha, representam penalidades por comportamentos não condizentes com uma postura ambientalmente correta. As penalidades são do tipo ande uma casa para trás ou fique sem jogar uma rodada.

\section{AVALIANDO A PRÁTICA PEDAGÓGICA}

As idas à escola e os contatos com a turma permitiram que o licenciando avaliasse as atividades didáticas desenvolvidas. O primeiro questionário, de avaliação diagnóstica, pode constatar que os alunos possuíam fracos conhecimentos dos temas ambientais identificado que a aquisição do conhecimento se deu de maneira informal. Os conhecimentos prévios presentes nas respostas dos 19 questionários analisados contribuíram para a escolha dos temas desenvolvidos nas aulas expositivas. Ficou evidente que não existiam na escola projetos de educação ambiental.

A educação ambiental deve tratar das questões globais críticas, suas causas e inter-relações em uma perspectiva sistêmica, em seu contexto social e histórico. $\mathrm{Na}$ visão ambiental é preciso diagnosticar que tipo de conceitos os alunos formaram e como 
eles percebem a sua participação nas transformações que ocorrem no planeta. Algumas respostas do primeiro questionário identificaram que os alunos não tinham consciência da importância da preservação da água como um recurso finito. Só $32 \%$ dos alunos se preocupa com a coleta seletiva e ainda, $68 \%$ dos alunos responsabilizam a sociedade, em geral, pelos danos causados ao meio ambiente, demonstrando que existe sim uma consciência com relação a sua participação no ambiente em que vivem.

Na pergunta onde se pretendeu identificar qual o setor da economia causa menos impactos negativos ao meio ambiente foi observado que para a turma o setor agrícola é o que está mais envolvido com a preservação do meio ambiente, o que demonstra a falsa relação homem-natureza. Como o setor agrícola está relacionado a áreas verdes há uma associação de que área verde é igual à natureza para muitos alunos. A questão sobre a vivência de projetos de EA desenvolvidos na escola identificou que somente $44 \%$ dos alunos participaram de alguma atividade relacionada ao meio ambiente. Infelizmente, hoje ainda faltam iniciativas de professores, diretores de escolas para desenvolver projetos, atividades e trabalhos que contribuam para a formação de cidadania do aluno. Embora a educação ambiental prescinda de ações multidisciplinares, ainda hoje se observa uma total falta de articulação para a prática da EA. Para a questão aberta onde se perguntou "Qual o principal recurso que é economizado quando se recicla uma latinha de alumínio?" nenhuma das respostas identificou economia de energia.

O segundo questionário mostrou que $70 \%$ dos alunos, num universo de 22 alunos, melhoraram a sua percepção quanto aos temas ambientais e conseguiram associar a presença da química nas situações ambientais, mostrando que a contextualização dos conteúdos foi compreendida. Para avaliar o jogo como um recurso didático foram formuladas três questões. Na questão 1, "Você achou que o jogo permitiu aumentar o seu conhecimento sobre os temas ambientais abordados nas palestras"? A afirmativa foi de $88 \%$ dos alunos onde, responderam que palestras informativas com a temática ambiental são também importantes. Este resultado demonstra um interesse dos alunos na ampliação do conhecimento ambiental, pois a informação ajuda a desenvolver ações para a defesa e conservação do meio ambiente. Neste contexto, também passa para o licenciando a certeza de que a educação é a forma mais sólida para caminhar para o desenvolvimento sustentável, já que fornece subsídios para a formação de um cidadão pensante, crítico e capaz de realizar ações em prol do seu bem estar e do meio que o cerca. 
Na opinião dos alunos, $89 \%$ das respostas indicaram que o jogo despertou o interesse e a competitividade avaliada pela questão 2 . A questão 3 obteve $95 \%$ de concordância quanto à utilização de um recurso lúdico com a finalidade de despertar para a reflexão e o conhecimento.

Analisando os resultados dos questionários e a receptividade da turma para a atividade proposta ficou evidente que os alunos gostaram do jogo, ficaram estimulados a jogar, pois durante sua aplicação à turma demonstrou interesse em responder corretamente as questões. A função educativa do jogo foi facilmente observada durante sua aplicação verificando-se que ela favorece a aquisição e retenção de conhecimentos. Além de demonstrarem nas aulas interesse e participação com perguntas e comentários.

\section{CONSIDERAÇÕES FINAIS}

O processo de aprendizagem é, portanto, configurado pelo desenvolvimento de formas e conteúdos, validados pela experiência, o que produz um processo de reflexão e de pesquisa da sua futura prática pedagógica.

\footnotetext{
Reconhecemos que o exercício da Educação Ambiental tem encontrado dificuldades que estão associadas à falta de recursos, à pouca valorização do professor, ao pouco envolvimento da comunidade nas decisões e no planejamento escolar, aliada à própria rigidez da estrutura de grande parte das escolas. Outras questões relacionadas à prática pedagógica também devem ser lembradas como a visão "conteudista" que predomina no ensino tradicional, a pouca preparação dos professores e os critérios de avaliação comumente adotados, em que predominam ausência de criatividade e uma visão não processual (MORADILHO, 2004)
}

A aproximação do licenciando com o cenário escolar, para desenvolver pesquisas relativas à sua própria prática pedagógica, favoreceu a constituição de uma prática reflexiva para o professor em formação. Este pode perceber que a atividade do professor em sala de aula agrega muitas especificidades e que os conteúdos químicos podem ser articulados perfeitamente com a sociedade e a temática ambiental pela compreensão do modo como a química influencia a interpretação do mundo atual, condicionando formas de pensar e interagir.

A análise dos questionários aplicados na escola, suas implicações, a divulgação dos resultados da experiência vivida na escola formalizados na monografia de conclusão de curso do licenciando permitiu o desenvolvimento de habilidades que capacitam o futuro professor para desenvolver pesquisa em ensino. Cobrindo assim, uma possível 
lacuna na formação docente inicial, já que as disciplinas oferecidas na Universidade não vão dar conta de formar um profissional com as características desejadas para uma prática docente mais comprometida coma formação da cidadania.

Neste cenário, a escolha dos temas ambientais e a forma de apresentá-los, através de momentos mais interativos e dialógicos, articulados com o ensinos de química permitem que se promova a formação de sujeitos críticos-reflexivos, capazes de atuarem como agentes transformadores da sociedade.

As perspectivas de ampliação do conhecimento produzido através da construção de uma nova forma de inserir uma prática pedagógica lúdica, que é um jogo didático, são muito grandes, pois a trilha pode ser aplicada pelo professor utilizando diferentes temáticas com diferentes níveis de conhecimento o que permitirá a aplicação desta dinâmica em diferentes séries do ensino médio. A simples reformulação das perguntas adequando-as para o conteúdo desenvolvido pode ser avaliado como uma nova ferramenta de avaliação dos conteúdos apresentados. Por outro lado, a aplicação do jogo não se esgota, podendo evoluir para uma forma de uma mídia digital interativa.

A iniciativa de um projeto investigativo realizado por um professor em formação, sem os vícios de práticas ultrapassadas permite a constituição de novas inserções pedagógicas futuras, que otimizam e propiciam aulas mais interativas e dialógicas, articuladas com os novos rumos da sociedade, que caminham na direção de um ensino de ciências que promova a formação de sujeitos capazes de atuarem como agentes transformadores do seu meio.

\section{REFERÊNCIAS}

BRASIL, PCN Temas Transversais. 1988, 108, 3335

BRASIL. Lei Federal 9.795, de 27 de abril de 1999. Dispõe sobre educação ambiental. Disponível em <http://www.planalto.gov.br/>. Acessado em 9 de junho de 2008.

CAMPOS, L. M. L.; FELICIO, A. K. C.; BORTOLOTTO, T. M. A produção de jogos didáticos para o ensino de Ciências e Biologia: uma proposta para favorecer a aprendizagem. Caderno dos Núcleos de Ensino, 2003, p. 35-48.

DEMO, P. Educar pela Pesquisa. Campinas: Autores Associados, 1996. 
DIAZ, G.F. Educação Ambiental: Princípios e Práticas. 5. ed. São Paulo, 1998.

LÜDKE, M. e ANDRÉ, M. A Pesquisa em Educação: uma abordagem qualitativa. São Paulo: EPU, 1986

MORADILLO, Edison Fortuna; OKI, Maria da Conceição Marinho. Educação ambiental na universidade: construindo possibilidades. Quim. Nova, Vol. 27, No. 2, 332336, 2004

OVALES, Omar; VIEZZER Moema. Manual latino americano de educação ambiental. São Paulo: Gaia,1995.

VIGOTSKI, Liev Seminovich. Psicologia Pedagógica ed. comentada. Porto Alegre, RS: Artemed.2003. 